\title{
Fermented wheat aleurone inhibits growth and induces apoptosis in human HT29 colon adenocarcinoma cells
}

\author{
Anke Borowicki $^{1 *}$, Katrin Stein ${ }^{1}$, Daniel Scharlau ${ }^{1}$, Kerstin Scheu ${ }^{2}$, Gerald Brenner-Weiss ${ }^{2}$, Ursula Obst ${ }^{2}$, \\ Jürgen Hollmann ${ }^{3}$, Meinolf Lindhauer ${ }^{3}$, Norbert Wachter ${ }^{4}$ and Michael Glei ${ }^{1}$ \\ ${ }^{1}$ Department of Nutritional Toxicology, Friedrich-Schiller-University Jena, Institute for Nutrition, Dornburger Strasse 24, \\ 07743 Jena, Germany \\ ${ }^{2}$ Department of Microbiology of Natural and Technical Interfaces, Research Centre Karlsruhe, Institute of Functional Interfaces \\ (IFG), Hermann-von-Helmholtz-Platz 1, 76344 Eggenstein-Leopoldshafen, Germany \\ ${ }^{3}$ Max Rubner-Institute, Federal Research Institute of Nutrition and Food, Schützenberg 12, 32756 Detmold, Germany \\ ${ }^{4}$ Kampffmeyer Food Innovation GmbH, Trettaustr. 32-34, 21107 Hamburg, Germany \\ (Received 27 March 2009 - Revised 14 July 2009 - Accepted 3 August 2009 - First published online 7 September 2009)
}

Fermentation of dietary fibre by the gut microflora may enhance levels of SCFA, which are potentially chemoprotective against colon cancer. Functional food containing wheat aleurone may prevent cancer by influencing cell cycle and cell death. We investigated effects of fermented wheat aleurone on growth and apoptosis of HT29 cells. Wheat aleurone, flour and bran were digested and fermented in vitro. The resulting fermentation supernatants (fs) were analysed for their major metabolites (SCFA, bile acids and ammonia). HT29 cells were treated for 24-72 h with the fs or synthetic mixtures mimicking the fs in SCFA, butyrate or deoxycholic acid (DCA) contents, and the influence on cell growth was determined. Fs aleurone was used to investigate the modulation of apoptosis and cell cycle. The fermented wheat samples contained two- to threefold higher amounts of SCFA than the faeces control (blank), but reduced levels of bile acids and increased concentrations of ammonia. Fs aleurone and flour equally reduced cell growth of HT29 more effectively than the corresponding blank and the SCFA mixtures. The EC 50 (48 h) ranged from $10 \%$ (flour) to $19 \%$ (blank). Markedly after $48 \mathrm{~h}$, fs aleurone (10\%) significantly induced apoptosis and inhibited cell proliferation by arresting the cell cycle in the G0/G1 phase. In conclusion, fermentation of wheat aleurone results in a reduced level of tumour-promoting DCA, but higher levels of potentially chemopreventive SCFA. Fermented wheat aleurone is able to induce apoptosis and to block cell cycle - two essential markers of secondary chemoprevention.

Aleurone: Apoptosis: Cell cycle: Colon cancer: Fermentation

Colorectal cancer (CRC) is the second most common type of cancer worldwide in both men and women and accounts yearly for $9 \%$ of all new cases of cancer ${ }^{(1)}$. Most CRC are sporadic, with dietary factors being among the most important risk factors. Latest epidemiological and preclinical studies revealed that an increased intake of dietary fibre can influence normal human gut function as well as intestinal flora and may modulate colon cancer risk ${ }^{(2)}$. Dietary fibre exerts several effects in the gastrointestinal tract, but the precise mechanisms for this protective role are not clearly understood. The mechanisms by which dietary fibre may reduce the risk of CRC include stool bulking (diluting faecal content and shortening transit time), binding luminal potential carcinogens like secondary bile acids and lowering faecal $\mathrm{pH}^{(3)}$. A further mechanism by which dietary fibre could improve colonic health is by acting as a substrate for luminal health-promoting bacteria species to increase fermentation products mainly SCFA, particularly acetate, propionate and butyrate. Butyrate is considered as the major energy source for normal, non-transformed colonocytes and has received much attention as a potential chemopreventive agent by inhibiting promotion and progression or by removing degraded cells from the tissue ${ }^{(4)}$.

Butyrate inhibited histone deacetylases resulting in histone hyperacetylation, which can lead to transcriptional modulation and silencing of genes that are involved in control of cell cycle progression, differentiation, apoptosis and cancer development ${ }^{(3,5)}$.

Under physiological conditions, butyrate affects human colon cells not separately but rather in conjunction with other fermentation products, which are formed simultaneously by microbial degradation of dietary fibre. Detailed evidence is limited on how fermentation products from dietary fibre sources such as grains interact with human intestinal cells and how these fermentation supernatants (fs) affect cells in comparison to analogous SCFA concentrations or butyrate alone ${ }^{(6,7)}$. Fermentation products can be generated in vitro using batch models that simulate the physiological conditions

Abbreviations: CRC, colorectal cancer; DCA, deoxycholic acid; EU, European; fs, fermentation supernatant; US, American.

* Corresponding author: Anke Borowicki, fax +49 36419496 72, email anke.borowicki@uni-jena.de 
of the human gastrointestinal tract. This provides an experimental approach to compare the biological activities of foodstuffs rich in dietary carbohydrates in terms of their fermentation products and interactions of these products ${ }^{(8,9)}$. Wheat grain contains high amounts of dietary fibre and other physiologically beneficial substances. In wheat grains, aleurone is a unicellular layer that forms the outer part of the endosperm. The aleurone layer makes up 7-9\% of the kernel and $45-50 \%$ of the bran fraction and contains the major portion of the physiologically relevant substances found in the whole grains in a concentrated form, namely dietary fibre, minerals, B-vitamins, proteins and secondary plant compounds $^{(10,11)}$. Several epidemiological and experimental studies indicated that wheat bran as a source of dietary fibre is one of the most effective parts of the whole grain in protecting against $\mathrm{CRC}^{(12,13)}$. The main components of the dietary fibre fraction are predominantly arabinoxylans, followed by cellulose, $\beta$-glucans and starch, whereas the ratio of insoluble to soluble fibre is in the order of $9: 1^{(11)}$. Reddy et al. ${ }^{(14)}$ showed that wheat bran, but not oat or maize bran, significantly decreased the levels of several tumour promoters in the colon. It was assumed that this protective mechanism is most likely multifactorial, because differences could be caused by the slower degradation of wheat bran by colonic microflora or additional effects of phytoprotectants, although there is only few data to support this ${ }^{(13)}$. In the aleurone layer, ferulic acid is the major phenolic compound largely ester linked to arabinoxylans ${ }^{(11,12)}$. The protective potential of this natural antioxidant depends on the fermentability, because digestive processes increase the antioxidative activity of wheat and wheat-based products ${ }^{(15)}$. In human subjects, more than $95 \%$ of the enzymatic release of ferulic acid occurs in the colon $^{(15)}$. Thus, antioxidative compounds may enhance chemopreventive effects of fermentation products of dietary fibre.

The first goal of the present work was to use a modified 'batch' model simulating the whole digestive tract to characterise and compare fermentation products of three wheat sources, namely aleurone, bran and flour, on parameters of chemoprevention, more precisely enhancement of healthpromoting metabolites and reduction in tumour-promoting faecal products. Secondly, the effect of fs and relevant concentrations of SCFA (acetate, propionate and butyrate) as well as deoxycholic acid (DCA) on cell growth of HT29 colon tumour cells was studied. Beyond this, fermented European (EU) and American (US) aleurone were used to determine modulation of cell cycle and apoptosis, because dysfunction of the balance between cell growth and death in colonic epithelium is associated with cancer promotion. Understanding how this balance is influenced by interaction of specific dietary components, especially fermentation products, could lead to improved treatment and prevention strategies for cancer since there is considerable evidence from animal experiments that prebiotics are chemoprotective in the later phases of carcinogenesis ${ }^{(14)}$.

\section{Materials and methods}

\section{Dietary fibre sources}

Three different wheat fractions (aleurone, bran and flour) of two varieties (EU and US) were used as dietary fibre sources. All were from Kampffmeyer Food Innovation $\mathrm{GmbH}$
(Hamburg, Germany). To guarantee the stability of the wheat samples, aliquots were prepared and stored in air- and light-proof flasks at $4^{\circ} \mathrm{C}$.

\section{Analysis of dietary fibre sources}

Analysis of dietary fibre was performed according to standard method AOAC Official Methods of Analysis no. 985.29 and no. 991.43, respectively. Arabinoxylans were analysed according to Hollmann et al. ${ }^{(16)}$. Analysis of crude ash, $\beta$-glucans and protein was performed according to standard method ICC no. 104/1, no. 166 and no. 167, respectively. Concentration of starch was determined according to standard method EWG, VO 228/67. D-glucose was analysed by highperformance anion-exchange chromatography on a DIONEX BioLC system (DIONEX Corporation, Sunnyvale, CA, USA) according to Hollmann et al. ${ }^{(16)}$. Analysis of crude fat was performed by Soxhlet extraction of lipids with petroleum ether (flash point $40-60^{\circ} \mathrm{C}$ ) for $4 \mathrm{~h}$ and gravimetric determination of the dried residue.

\section{Digestion and fermentation of wheat components}

Aleurone (EU and US), flour (EU) and bran (EU) were digested and fermented in vitro according to the described procedures of Aura et al. ${ }^{(9)}$ and Glei et al. ${ }^{(17)}$ with some modifications. Two fermentation series (each $n$ 6) were used to study the effects of fermented wheat components. In fermentation I, EU aleurone, EU flour and EU bran were digested and fermented in vitro, whereas in fermentation II, EU aleurone and US aleurone were used.

Briefly, for simulation of the whole digestive tract, samples were weighed $(0.5 \mathrm{~g}$ fermentable sample), mixed thoroughly with $10 \mathrm{ml}$ PBS (0.1 M, pH 7.0), and $0.85 \%$ (w/v) saline solution $(6.25 \mathrm{ml})$ was added to the samples. A sample without wheat was used (blank - faeces control) as a control. All incubation steps were performed at $37^{\circ} \mathrm{C}$ in a shaking water-bath under the same conditions. Salivary $\alpha$-amylase (Sigma A-0521) diluted to $1000 \mathrm{U} / \mathrm{ml}$ with $20 \mathrm{~mm}$ sodium phosphate buffer was added (17.36 U/sample), and the samples were incubated for $5 \mathrm{~min}$. $\mathrm{HCl}$ solution $(150 \mathrm{mM}, 2 \cdot 8125 \mathrm{ml})$ was added to lower $\mathrm{pH}$ to $2 \cdot 0$. Pepsin (Sigma P-7012, $1.11 \mathrm{mg}$ ) dissolved in $0.9375 \mathrm{ml}$ of $20 \mathrm{mM} \mathrm{HCl}$ per sample or blank was added and incubated for $2 \mathrm{~h}$. Intestinal extract was produced by dissolving $3 \mathrm{mg}$ ox gall (Fluka-Sigma 70 168) and $2.6 \mathrm{mg}$ pancreatin (Sigma P-1750) in $5 \mathrm{ml}$ sodium bicarbonate buffer (11 mM, pH 6.5). Intestinal extract was added to each sample or blank, the $\mathrm{pH}$ was adjusted to 6.5 using $\mathrm{NaOH}$ solution $(10 \mathrm{M})$ and the suspension $(25 \mathrm{ml})$ was filled into a dialysis tube (Roth, 4596.1, molecular weight cut-off $1000 \mathrm{Da})$. The tubes were placed into glass bottles filled with 2 litre dialysis buffer $(13.61 \mathrm{~g}$ potassium phosphate and $1.88 \mathrm{~g}$ sodium bicarbonate dissolved in distilled water, $\mathrm{pH}$ 6.5) and incubated for $6 \mathrm{~h}$ at $37^{\circ} \mathrm{C}$ under semi-anaerobic conditions. Semi-anaerobic conditions in the glass bottles were achieved by removing a part of the air with an injected cannula $(0.5$ bar for $1 \mathrm{~min})$. Subsequently, the bottles were filled with a fermentation gas mixture $\left(86 \% \mathrm{~N}_{2}, 10 \% \mathrm{CO}_{2}\right.$ and $\left.4 \% \mathrm{H}_{2}\right)$ via the cannula $(0.8 \mathrm{bar}$ for $1 \mathrm{~min})$. After $15 \mathrm{~min}$ (seven cycles repeated), the cannulae were removed. At the end of the incubation, the suspension was transferred from 
the dialysis tube into a $500 \mathrm{ml}$ glass bottle and the $\mathrm{pH}$ was measured for each sample. The in vitro fermentation was performed as described by Glei et al. ${ }^{(17)}$ with slight modifications. All fermentations were conducted under anaerobic conditions at $37^{\circ} \mathrm{C}$ for $24 \mathrm{~h}$. The fermentation process was stopped by placing the suspensions on ice and the $\mathrm{pH}$ was measured. Each sample was transferred to $50 \mathrm{ml}$ tubes and centrifuged $\left(4200 \mathrm{~g}, 4^{\circ} \mathrm{C}\right)$ for $30 \mathrm{~min}$. The supernatants were transferred into new $50 \mathrm{ml}$ tubes and centrifuged again $\left(4200 \mathrm{~g}, 4^{\circ} \mathrm{C}\right)$ for $15 \mathrm{~min}$ and stored at $-80^{\circ} \mathrm{C}$. The fs were pooled after finishing one fermentation series to minimise effects of individual nutrition. Before sterilisation of the fs, the samples were thawed quickly, aliquoted in $2 \mathrm{ml}$ tubes and centrifuged $\left(16000 \mathrm{~g}, 4^{\circ} \mathrm{C}\right)$. Afterwards, the fs were sterilised by filtration (pore size, $0.22 \mu \mathrm{m}$ ) to get final fs for use in the cell culture experiments.

\section{Determination of $\mathrm{pH}$ and analysis of fermentation products}

The $\mathrm{pH}$ was determined with a $\mathrm{pH}$ meter Hydrus 300 (Fisherbrand, Schwerte, Germany).

SCFA concentrations were determined by GC combined with MS (GC-MS) as described by Wang et al. ${ }^{(18)}$ with some modifications. In short, SCFA were extracted from diluted fs (1:50 in fermentation buffer) via liquid-liquid with tert-butyl methyl diethyl ether using 2-ethyl butyric acid as the internal standard. About $1 \mathrm{ml}$ of the combined organic phase was derivatised with $20 \mu \mathrm{l}$ trimethylsulfonium hydroxide solution (Sigma $92723)$ in methanol $(10 \% \mathrm{v} / \mathrm{v})$ for $20 \mathrm{~min}$ at room temperature. GC-MS was performed with a Star 3400cx and Saturn 2000 (Varian, Palo Alto, CA, USA). About $2 \mu \mathrm{l}$ aliquots of the derivatisated samples were injected onto a Stabilwax-DA column (Restek, Bellefonte, PA, USA, $30 \mathrm{~m} \times 0.25 \mathrm{~mm}$ internal diameter $\times 0.25 \mu \mathrm{m})$ using helium gas as carrier. The chromatographic conditions were as follows: $60^{\circ} \mathrm{C}$ held for $2 \mathrm{~min}$, $+10^{\circ} \mathrm{C} / \mathrm{min}$ until $150^{\circ} \mathrm{C}$ held for $1 \mathrm{~min}$ and $+50^{\circ} \mathrm{C} / \mathrm{min}$ until $240^{\circ} \mathrm{C}$ held for $10 \mathrm{~min}$. For the detection of the SCFA, the mass spectrometer was used in full scan mode.

Bile acids were determined similar to the procedure of Burkard et al. ${ }^{(19)}$. Briefly, after dilution of the fs $(1: 10$ in fermentation buffer), solid phase extraction was carried out using 101 sorbent cartridges (Separtis, Grenzach-Wyhlen, Germany) and cholic acid- $\mathrm{d}_{4}$ as an internal standard. The eluted bile acids were separated on an RP-C8 column (100 $\times 4 \mathrm{~mm}, 5 \mu \mathrm{m}, \mathrm{MZ}-$ Analysentechnik, Mainz, Germany), using $10 \mathrm{~mm}$ ammonium acetate buffer (pH 5) containing $0.012 \%$ formic acid (eluent A) and acetonitrile (eluent B) as a mobile phase at a flow rate of $0.5 \mathrm{ml} / \mathrm{min}$. The eluents were linearly changed from $70 \% \mathrm{~A}$ and $30 \% \mathrm{~B}$ to $30 \%$ $\mathrm{A}$ and $70 \% \mathrm{~B}$ within $38 \mathrm{~min}$, held for $10 \mathrm{~min}$ and finally adjusted to the original ratio of $70 \% \mathrm{~A}$ and $30 \% \mathrm{~B}$ for $15 \mathrm{~min}$ for equilibration. The detection of bile acids was performed with a tandem mass spectrometer API $4000^{\mathrm{TM}}$ (Applied Biosystems/MDS SCIEX, Toronto, Ont., Canada), equipped with an ESI ionisation source operating in the negative mode at $-4.5 \mathrm{kV}$ at $450^{\circ} \mathrm{C}$. Bile acids were quantified by external calibration in the MRM mode using the Analyst 1.4 (Applied Biosystems/MDS SCIEX).

The ammonia concentration of the resulting fs was determined colorimetrically by the Berthelot reaction, in which ammonia is converted into a blue-coloured indophenol ion $^{(20)}$. For this, the fs were diluted $1: 1000$ in aqua bidest, and $2 \mathrm{ml}$ solution $1(0 \cdot 1 \mathrm{~g} / 1$ phenol and $0.5 \mathrm{mg} / \mathrm{l}$ sodium nitroprusside dissolved in aqua bidest) and $2 \mathrm{ml}$ solution $2(0.05 \mathrm{~g} / \mathrm{l}$ $\mathrm{NaOH}$ and $4 \mathrm{mg} / \mathrm{l}$ sodium hypochlorite dissolved in aqua bidest) were added. Subsequently, samples were incubated for $10 \mathrm{~min}$ at $60^{\circ} \mathrm{C}$ and thereafter cooled down to room temperature. The samples $(200 \mu \mathrm{l} /$ cavity) were transferred into ninety-six-well plates, and the extinction at $630 \mathrm{~nm}$ was measured in triplicates (GENios, Tecan Germany GmbH, Crailsheim, Germany).

\section{Preparation of synthetic mixtures and of aqueous extracts of wheat fractions}

Sodium butyrate and sodium acetate were obtained from Merck-Schuchardt (Hohenbrunn, Germany) whereas sodium propionate and DCA were from Sigma-Aldrich Chemie $\mathrm{GmbH}$ (Steinheim, Germany). All chemicals were of the highest commercially available grade of purity. SCFA and DCA were weighed and dissolved in Dulbecco's modified Eagle's medium (DMEM, Gibco BRL, Eggenstein, Germany), supplemented with $10 \%$ fetal calf serum to obtain corresponding mixtures containing identical concentrations and ratios of SCFA and DCA as the particular fs. Mixtures or individual substances were used for cell culture incubation experiments.

Aleurone, flour and bran of both varieties (EU and US) were weighed and mixed thoroughly for $30 \mathrm{~s}$ with supplemented DMEM $(100 \mathrm{~g} / \mathrm{l})$ according to Glei et al. ${ }^{(21)}$.

\section{Cell culture}

The human colon adenocarcinoma cell line HT29 (American Type Culture Collection (ATCC) no. HTB-38) was used for all cell culture experiments ${ }^{(22)}$ (passages 12-47). In regular intervals, a mycoplasma test (MycoAlert ${ }^{\mathrm{TM}}$ Detection Kit) was performed and contamination with mycoplasma was excluded.

\section{Determination of cell growth}

HT29 cells were incubated with fs $24 \mathrm{~h}$ after seeding in ninetysix-well plates. Concentrations between 2.5 and $20 \%$ of fs and corresponding concentrations of synthetic mixtures as well as individual substances were tested. After 24,48 or $72 \mathrm{~h}$ of incubation, the amount of DNA, which is related to the number of cells, was quantified as described previously ${ }^{(17)}$. The results were calculated on the basis of the medium control that was set to equal $100 \%$. In comparison to the fs, the aqueous extracts of unfermented wheat samples (0.05-40 g/l) were analysed for their influence on cell number. The effective mean doses $\left(\mathrm{EC}_{50}\right)$ of fs and aqueous extracts that inhibited growth by $50 \%$ were determined and expressed as percentage $(\%)$ and gram/litre (g/l), respectively.

\section{Determination of genotoxicity}

To determine the genotoxic potential of the fs, $1 \times 10^{6}$ cells were seeded in six-well plates $24 \mathrm{~h}$ before the experiment. The cells were incubated with different concentrations ( 5 and $10 \%$ ) of fs aleurone or fs blank for $1 \mathrm{~h}$ (short term) or $24 \mathrm{~h}$ (long term). Subsequently, the cells were trypsinised and dissolved in PBS. Hydrogen peroxide $\left(150 \mu \mathrm{M} ; 5\right.$ min at $\left.4^{\circ} \mathrm{C}\right)$ 
was used as positive control. Viabilities and cell numbers were determined with a CASY-cell counter $\left(\mathrm{CASY}^{\circledR}\right.$-TT, Innovatis AG, Reutlingen, Germany), and $0.4 \times 10^{6}$ cells were mixed with $0.7 \%$ low-melting agarose (Biozym, 850.110) dissolved in PBS and distributed onto microscopical slides followed by application of another layer of low-melting agarose. The further steps were carried out as described elsewhere ${ }^{(17,21)}$.

\section{Cell cycle analysis}

For analysis of cell cycle parameters, the cells were seeded in six-well plates $\left(1.5 \times 10^{6}\right.$ cells/well $)$ and grown for $24 \mathrm{~h}$ before exposition to fs (5 and $10 \%$ ) or corresponding synthetic SCFA mixtures $(10 \%)$ and butyrate $(10 \%)$ for 24 or $48 \mathrm{~h}$. Subsequently, the cells were trypsinised and dissolved in PBS. Viabilities and cell numbers were determined with a CASY-cell counter and $2 \times 10^{6}$ cells were stained with nuclear isolation medium-4,6-diamidino-2-phenylindole dihydrochloride (NIM-DAPI) $(0.6 \%$ Nonidet P40 and $10 \mu \mathrm{g} / \mathrm{ml}$ DAPI dissolved in PBS). After incubation for $10 \mathrm{~min}$, intercalated DAPI was quantified by flow cytometry, whereas counted cells were allocated to specified phases of cell cycle using cytometry analysis software (Cell Lab Quanta ${ }^{\mathrm{TM}}$ SCMPL 1.0, Beckman Coulter, Krefeld, Germany).

\section{Detection of apoptosis}

Cells were seeded in six-well plates $\left(1.5 \times 10^{6}\right.$ cells/well $)$ and grown for $1 \mathrm{~d}$ before exposition to fs $(10 \%)$ or corresponding concentrations of synthetic SCFA mixtures and butyrate for 24 and $48 \mathrm{~h}$. Subsequently, the cells were trypsinised and dissolved in PBS. Viabilities and cell numbers were determined with a CASY-cell counter, and $1 \times 10^{6}$ cells were stained with annexin V-FITC as well as 7-amino-actinomycin $\mathrm{D}$ in annexin V-binding buffer using the annexin V-FITC/ 7-amino-actinomycin D kit (Beckman Coulter). After incubation for $15 \mathrm{~min}$, apoptosis was quantified by flow cytometry and counted cells were classified using cytometry analysis software (Cell Lab Quanta ${ }^{\mathrm{TM}}$ SC-MPL 1.0, Beckman Coulter). Enzyme activity of caspase-9, caspase- 8 and caspase- 3 was determined to obtain more detailed information on the induction of apoptosis. Therefore, cells were treated as described above, and $2.4 \times 10^{6}$ cells were lysed for $20 \mathrm{~min}$ at $4^{\circ} \mathrm{C}$ in a cell lysis buffer (250 mM HEPES, 25 mm 3-[(3-cholamidopropyl)-dimethylamino]-2-hydroxy-1-propanesulfonate (CHAPS), $25 \mathrm{mM}$ threo-1,4-dimercapto-2,3-butanediol (DTT), $1 \mu \mathrm{g} / \mathrm{ml}$ leupeptin, $1 \mu \mathrm{g} / \mathrm{ml}$ pepstatin A, $100 \mu \mathrm{g} / \mathrm{ml}$ pefabloc $\mathrm{SC}$, $1 \mathrm{mM}$ phenylmethylsulfonylfluoride (PMSF) and $1 \mathrm{mM}$ sodium orthovandate). After centrifugation at $16000 \mathrm{~g}$ for $15 \mathrm{~min}$ at $4^{\circ} \mathrm{C}$, half of each lysate was incubated with $50 \mathrm{~nm}$ caspase inhibitors (caspase-3: Ac-DEVD-CHO; caspase-9: Ac-LEHD-CHO; caspase-8: Ac-IETD-CHO, Axxora GmbH, Lörrach Germany) for $10 \mathrm{~min}$, followed by incubation with $25 \mu \mathrm{M}$ caspase substrate (caspase-3: Ac-DEVD-AMC; caspase-9: Ac-LEHD-AMC; caspase-8: Ac-IETD-AMC, Axxora $\mathrm{GmbH}$ ) for $2 \mathrm{~h}$ at $37^{\circ} \mathrm{C}$ for all cell lysates. Modulation of caspase activity was detected by fluorimetrical analysis with Ex/Em 380/465 nm (SpectraFluor Plus, Tecan Germany $\mathrm{GmbH}$, Crailsheim, Germany). For interpretation of all results, fold changes were calculated on the basis of the medium control that was set to $1 \cdot 0$.

\section{Statistical evaluation}

Means and standard deviations were calculated from at least three independent experiments. Differences were calculated by one- or two-way ANOVA, including Bonferroni post test with selected pairs, using GraphPad Prism Version 4 for Windows (GraphPad Software, San Diego, CA, USA). The one-way ANOVA was done to define differences within one group if more than two concentrations were used. The twoway ANOVA was used to define differences between two groups if more than two concentrations were used. Otherwise comparisons of two groups were done with Student's $t$ test. The statistical analyses used depended on the respective experimental design and are specified in the legends to the figures and tables.

\section{Results \\ Composition of dietary fibre sources}

Generally, no large differences were seen in the composition of both wheat varieties (EU and US). In flour, starch was the major component $(66 \%)$, followed by protein $(16 \%)$, dietary fibre $(15 \%)$, crude fat $(3 \%)$ and crude ash $(<2 \%)$. Starch is the primary compound of the endosperm, which is the main part of the whole grain. Isolation of bran from whole grains resulted in increased amounts of all components except from starch $(14 \%)$. The bran fraction and the concentrated aleurone fraction primarily contained dietary fibre (56 and $47 \%$ ). Additionally, substantial amounts of protein (17 and $21 \%$ ), fat (5 and $6 \%$ ) and ash (6 and $10 \%)$ were present. Therefore, isolation of aleurone from bran resulted in an accumulation of protein, fat and ash. Furthermore, while levels of total dietary fibre were slightly reduced, water-soluble fibres were enriched in the aleurone fraction ( $3 \%$ in bran and $5 \%$ in aleurone). Arabinoxylans were the predominant fibres in the aleurone fraction with a quantity of nearly $55 \%$ of total dietary fibres, whereas less amounts of $\beta$-glucans were present $(9 \%)$.

\section{Fermentation products in fermentation supernatants of different wheat samples}

Table 1 compares the concentrations of various fermentation products and the measured $\mathrm{pH}$ in the fs of both fermentation series (I and II). Fermentation of the wheat samples resulted in significantly decreased $\mathrm{pH}(5 \cdot 15-5 \cdot 80)$ compared with fs blank (6.41-6.45). Lowered $\mathrm{pH}$ reflects the increased total concentration of the three SCFA acetate, propionate and butyrate. The fermented wheat samples contained two- to threefold higher amounts of SCFA than the fs blank. In particular, butyrate was increased three- to fivefold during fermentation, whereas the ratio of SCFA shifted from acetate to butyrate compared with fs blank. The analytical measurements of bile acids revealed low concentrations, and only $\mathrm{CA}$ and DCA were detectable. Both levels of the primary bile acid, CA, and particularly the secondary bile acid, DCA, were reduced compared to fs blank $(1 \cdot 3-2 \cdot 2$-fold and 3.5-13.8fold lower concentrations, respectively). By fermentation of the wheat samples, more ammonia was produced in correlation to contained protein amounts of the raw material. 
Table 1. Comparison of $\mathrm{pH}$, SCFA concentrations, ratio of SCFA as well as concentrations of bile acids and ammonia in fermentation supernatants (fs) after in vitro fermentation of different wheat fractions

(Mean values and standard deviations)

\begin{tabular}{|c|c|c|c|c|c|c|c|c|c|}
\hline & \multicolumn{2}{|c|}{$\mathrm{pH}$} & \multicolumn{3}{|c|}{ SCFA $(\mathrm{mm}) \dagger$} & \multirow[b]{2}{*}{ Ratio of SCFA (\%) } & \multicolumn{2}{|c|}{$\begin{array}{c}\text { Bile acids } \\
(\mu \mathrm{M}) \dagger\end{array}$} & \multirow[b]{2}{*}{ Ammonia $(\mathrm{mm}) \dagger$} \\
\hline & Mean & SD & Acetate & Propionate & Butyrate & & $\mathrm{CA}$ & DCA & \\
\hline \multicolumn{10}{|l|}{ Fermentation I } \\
\hline Blank & $6 \cdot 41^{\mathrm{a}}$ & 0.13 & $15 \cdot 24$ & 4.54 & $5 \cdot 82$ & $59: 18: 23$ & 0.24 & 35.41 & 10.87 \\
\hline EU aleurone & $5 \cdot 67^{\mathrm{b}}$ & 0.12 & $27 \cdot 56$ & $12 \cdot 20$ & 24.41 & $43: 19: 38$ & 0.18 & $10 \cdot 26$ & 18.53 \\
\hline EU flour & $5 \cdot 15^{\mathrm{b}}$ & 0.06 & 43.77 & 9.68 & $29 \cdot 72$ & $53: 11: 36$ & 0.11 & 2.57 & 11.64 \\
\hline EU bran & $5 \cdot 80^{\mathrm{b}}$ & 0.15 & 22.90 & 8.47 & $18 \cdot 42$ & $43: 19: 38$ & 0.18 & $9 \cdot 10$ & 14.56 \\
\hline \multicolumn{10}{|l|}{ Fermentation II } \\
\hline Blank & $6 \cdot 45^{\mathrm{a}}$ & 0.11 & $10 \cdot 75$ & 4.56 & 4.56 & $54: 23: 23$ & 0.35 & $46 \cdot 65$ & 11.92 \\
\hline EU aleurone & $5 \cdot 76^{\mathrm{b}}$ & 0.07 & 21.01 & $7 \cdot 12$ & $20 \cdot 32$ & $43: 15: 42$ & 0.20 & 5.04 & 16.63 \\
\hline US aleurone & $5 \cdot 78^{\mathrm{b}}$ & 0.06 & $25 \cdot 41$ & 9.06 & 24.23 & $43: 16: 41$ & 0.23 & 5.93 & $21 \cdot 28$ \\
\hline
\end{tabular}

CA, cholic acid; DCA, deoxycholic acid; EU, European; US, American.

${ }^{\mathrm{a}, \mathrm{b}}$ Mean values within a column with unlike superscript letters were significantly different $(P<0.001$; unpaired $t$ test).

† Because fs from six fermentations were pooled, only one determination in triplicate could be conducted. A statistical analysis was therefore not possible.

\section{Modulation of cell growth by fermentation supernatants (series I) and corresponding SCFA}

The fermentation series I was used to analyse the effect of different wheat fractions on cell growth. Treatment of HT29 cells with the fs of different wheat samples (aleurone, flour and bran) reduced the cell number in a time- and dosedependent manner. After $24 \mathrm{~h}$, the calculated $\mathrm{EC}_{50}$ (effective concentrations leading to a reduction of $50 \%$ in cell number) was not detectable for any fs, whereas after $48 \mathrm{~h}$, $\mathrm{EC}_{50}$ ranged from $10 \cdot 2$ to $19.0 \%$ (Table 2). After 48 and $72 \mathrm{~h}$ of treatment, fermented wheat samples reduced cell growth more effectively than fs blank. Significant differences between wheat fractions were seen for aleurone or flour and bran $(P<0.05)$ in lower concentrations (5 and 10\%). To evaluate which compounds are responsible for the cytotoxic effects of fs, synthetic mixtures of SCFA (acetate, propionate and butyrate), butyrate and propionate as well as butyrate alone mimicking the concentration in the fs were analysed for growth-inhibitory activities (Table 2). The growth of cells was efficiently retarded in HT29 cells by the SCFA mixtures, as well as mixtures of butyrate and propionate or butyrate as single substance of fermented wheat samples. Nevertheless, all synthetic mixtures were less effective than the fs, but the general profile of response was similar. No differences were seen between synthetic mixtures of fermented aleurone or flour. Higher concentrations of butyrate in fs flour $(30 \mathrm{~mm})$ compared with fs aleurone $(24 \mathrm{mM})$ did not result in an additional influence on cell growth. However, butyrate was still primarily responsible for the cytotoxic effect of fs. Acetate and propionate only slightly affected cell growth. Opposed to this, the inhibitory effect of fs blank was not only caused by the contained SCFA (Table 2). Fs blank significantly affected cell growth more than the synthetic mixtures.

Furthermore, the effects of DCA, a potential tumour-promoting fermentation metabolite, alone or in combination with SCFA, on cell growth of HT29 cells were analysed. Treatment with DCA $(<7 \mu \mathrm{M})$ alone did not modulate cell growth. Additionally, cytotoxic effects of SCFA were not enforced by the addition of the secondary bile acid DCA (data not shown). In general, the $\mathrm{pH}$ of the cell culture medium was not affected by the highest concentration of the fs used $(20 \%)$.

\section{Modulation of cell growth by fermentation supernatants (series II) and corresponding SCFA}

The fermentation series II was used to analyse the effect of different varieties of aleurone (EU and US) on cell growth. After treatment with the fs aleurone (EU and US), the number of HT29 cells was efficiently reduced in a time- and dose-dependent manner. The calculated $\mathrm{EC}_{50}$ ranged from 11.7 to $19.1 \%$ after $48 \mathrm{~h}$ (Table 3 ). No $\mathrm{EC}_{50}$ was, however,

Table 2. $E_{50}(\%)^{*}$ of fermentation supernatants (fs; series I) and corresponding synthetic mixtures SCFA (acetate, propionate and butyrate), propionate + butyrate and butyrate alone in HT29 cells

(Mean values and standard deviations)

\begin{tabular}{|c|c|c|c|c|}
\hline & \multicolumn{4}{|c|}{$\mathrm{EC}_{50}(\%)$} \\
\hline & \multicolumn{2}{|c|}{$48 \mathrm{~h}$} & \multicolumn{2}{|c|}{$72 \mathrm{~h}$} \\
\hline & Mean & SD & Mean & SD \\
\hline \multicolumn{5}{|l|}{ fs } \\
\hline Blank & $19 \cdot 0$ & $\dagger$ & $13 \cdot 4$ & $2 \cdot 7$ \\
\hline EU aleurone & $12 \cdot 0$ & $2 \cdot 2$ & $9 \cdot 4$ & $1 \cdot 2$ \\
\hline EU flour & $10 \cdot 2$ & 0.7 & $6 \cdot 1$ & 1.0 \\
\hline EU bran & $14 \cdot 5$ & 1.4 & $10 \cdot 9$ & 0.9 \\
\hline \multicolumn{5}{|l|}{ SCFA } \\
\hline Blank & $x$ & $x$ & $x$ & $x$ \\
\hline EU aleurone & $13 \cdot 5$ & $3 \cdot 6$ & $7 \cdot 2$ & $3 \cdot 1$ \\
\hline EU flour & $13 \cdot 4$ & $4 \cdot 2$ & $8 \cdot 5$ & $2 \cdot 1$ \\
\hline EU bran & ND & ND & ND & ND \\
\hline \multicolumn{5}{|c|}{ Propionate + butyrate } \\
\hline Blank & $x$ & $x$ & $x$ & $x$ \\
\hline EU aleurone & $15 \cdot 6$ & $3 \cdot 8$ & $8 \cdot 8$ & $3 \cdot 1$ \\
\hline EU flour & $14 \cdot 6$ & $3 \cdot 0$ & $8 \cdot 6$ & $2 \cdot 8$ \\
\hline EU bran & ND & ND & ND & ND \\
\hline \multicolumn{5}{|l|}{ Butyrate } \\
\hline Blank & $x$ & $x$ & $x$ & $x$ \\
\hline EU aleurone & $15 \cdot 4$ & $5 \cdot 6$ & $9 \cdot 6$ & 1.9 \\
\hline EU flour & $20 \cdot 0$ & $\dagger$ & $9 \cdot 4$ & 1.7 \\
\hline EU bran & ND & ND & ND & ND \\
\hline
\end{tabular}

EU, European

$\times$ Indicates that $\mathrm{EC}_{50}$ was not achieved.

${ }^{*} \mathrm{EC}_{50}$ is defined as effective concentration at which cell number decreased to $50 \%$ of viable cells.

† Standard deviation was not determinable because $\mathrm{EC}_{50}$ was not achieved in all three experiments. 
Table 3. $E_{50}(\%)^{*}$ of fermentation supernatants (fs; series II) and corresponding synthetic mixtures SCFA (acetate, propionate and butyrate), propionate + butyrate and butyrate alone in HT29 cells

(Mean values and standard deviations)

\begin{tabular}{|c|c|c|c|c|}
\hline & \multicolumn{4}{|c|}{$\mathrm{EC}_{50}(\%)$} \\
\hline & \multicolumn{2}{|c|}{$48 \mathrm{~h}$} & \multicolumn{2}{|c|}{$72 \mathrm{~h}$} \\
\hline & Mean & $\overline{\mathrm{SD}}$ & Mean & $\mathrm{SD}$ \\
\hline \multicolumn{5}{|l|}{ fs } \\
\hline Blank & $19 \cdot 1$ & $\dagger$ & $14 \cdot 1$ & 0.9 \\
\hline EU aleurone & $13 \cdot 6$ & 1.3 & 8.8 & 1.6 \\
\hline US aleurone & 11.7 & $1 \cdot 1$ & 8.2 & 1.4 \\
\hline \multicolumn{5}{|l|}{ SCFA } \\
\hline Blank & $x$ & $x$ & $x$ & $x$ \\
\hline EU aleurone & $x$ & $x$ & $14 \cdot 4$ & $4 \cdot 1$ \\
\hline US aleurone & $x$ & $x$ & $14 \cdot 6$ & 3.7 \\
\hline \multicolumn{5}{|c|}{ Propionate + butyrate } \\
\hline Blank & $x$ & $x$ & $x$ & $x$ \\
\hline EU aleurone & $x$ & $x$ & $17 \cdot 4$ & 1.5 \\
\hline US aleurone & $20 \cdot 0$ & $\dagger$ & $13 \cdot 8$ & 0.4 \\
\hline \multicolumn{5}{|l|}{ Butyrate } \\
\hline Blank & $x$ & $x$ & $x$ & $x$ \\
\hline EU aleurone & $x$ & $x$ & $17 \cdot 3$ & $\dagger$ \\
\hline US aleurone & $x$ & $x$ & $14 \cdot 8$ & $3 \cdot 2$ \\
\hline
\end{tabular}

EU, European, US, American

$\times \mathrm{EC}_{50}$ was not achieved.

${ }^{*} \mathrm{EC}_{50}$ is defined as effective concentration at which cell number decreased to $50 \%$ of viable cells.

† Standard deviation was not determinable because $\mathrm{EC}_{50}$ was not achieved in all three experiments.

detectable after $24 \mathrm{~h}$. The fermented aleurone affected the cell growth more effectively than fs blank independently of the variety after 48 and $72 \mathrm{~h}$ of treatment. Again, the growth of cells was efficiently retarded in HT29 cells by the SCFA mixtures (acetate, propionate and butyrate), as well as mixtures of butyrate and propionate or butyrate alone of both fs aleurone. The synthetic mixtures, however, were found to be slightly less effective than the respective fs in inhibiting growth of the cells. Higher concentrations of butyrate in fs US aleurone $(24 \mathrm{~mm})$ compared with fs EU aleurone $(20 \mathrm{~mm})$ had no increased influence on cell growth. Up to $65 \%$, butyrate was responsible for the cytotoxic effect of fs. Acetate and propionate had no clear additional effect on cell growth. Opposed to this, the cell-modulating effect of fs blank could not be explained by the contained SCFA (Table 3). Comparable to fermentation series I, fs blank had a significantly increased inhibitory effect on cell growth than the equivalent synthetic mixtures.

\section{Modulation of cell growth by aqueous extracts of wheat samples}

To determine the biological activity of the water-soluble compounds of the wheat samples (aleurone, flour and bran), the aqueous extracts were analysed for their influence on cell growth. Treatment of HT29 cells with the aqueous extracts of the wheat samples inhibited cell growth in a dose-dependent manner. After $24 \mathrm{~h}$, the calculated $\mathrm{EC}_{50}$ was not detectable for any extract, whereas after $48 \mathrm{~h}$, the $\mathrm{EC}_{50}$ was determinable only for EU aleurone $(22.7 \mathrm{~g} / \mathrm{l})$ and both varieties of bran (EU: $31.2 \mathrm{~g} / \mathrm{l}$; US: $39.3 \mathrm{~g} / \mathrm{l}$ ). EU aleurone was most effective compared with other fractions of the same variety or to US aleurone.

\section{Genotoxic potential of fermentation supernatants of different wheat samples}

Fs of both fermentation series were used to analyse the genotoxic potential of concentrations that were used in further experiments (5 and 10\%). Treatment of HT29 cells with fs of different wheat samples (5 and $10 \%$ ) for 1 or $24 \mathrm{~h}$ did not induce DNA damage as reflected by tail intensities below $5 \%$ (DNA in tail: $1 \mathrm{~h}, 1.92$ (SD 0.12) \% to 4.16 (SD 2.32$) \% ; 24 \mathrm{~h}, 1.79$ (SD 0.40$) \%$ to 3.57 (SD 1.87) \%).

\section{Modulation of cell cycle by fermentation supernatants of aleurone and corresponding SCFA mixtures}

The fs of different aleurone varieties were used to analyse their antiproliferative effect on HT29 cells, a relevant marker of secondary chemoprevention. In HT29 cells treated with fs aleurone $(10 \%)$ for $48 \mathrm{~h}$, an increased amount of cells in the G0/G1 phase was observed indicating a cell cycle arrest. This increase was accompanied by a decrease of cells in $\mathrm{S}$ and $\mathrm{G} 2 / \mathrm{M}$ phases (Fig. 1). In comparison, the fs blank $(10 \%)$, lower concentrations of the fs aleurone $(5 \%)$ or a shorter incubation time $(24 \mathrm{~h})$ did not influence the cell cycle progression. Mixtures with analogous SCFA
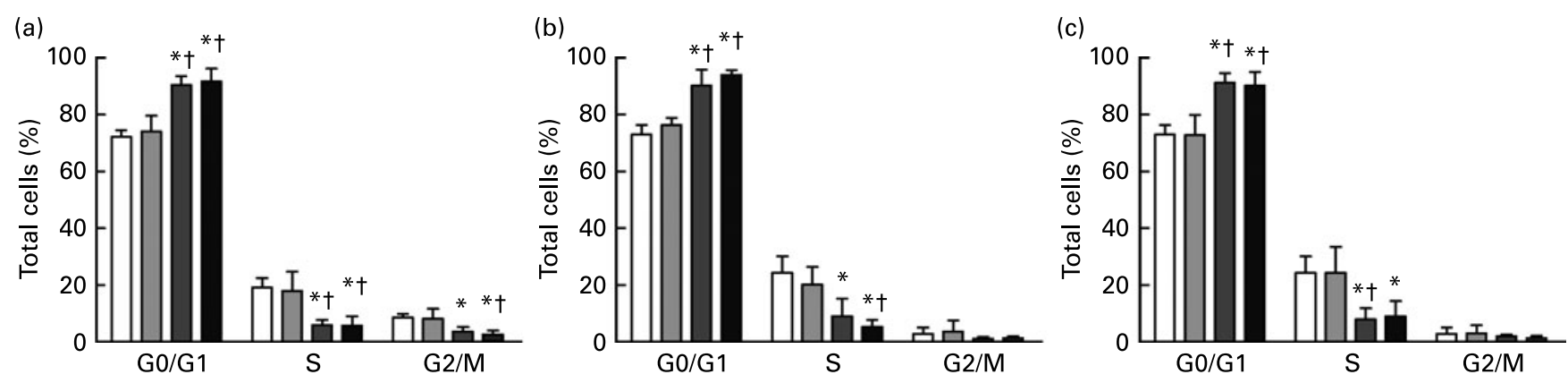

Fig. 1. Effects of medium control $(\square)$, blank $(\square)$, European aleurone $(\square)$ and American aleurone ( $\square$ ) on cell cycle phases (Go/G1; S; G2/M) in HT29 cells after treatment with fermentation supernatants (10\%) (a), the corresponding SCFA mixtures (acetate, propionate and butyrate) (b) and butyrate alone (c) for $48 \mathrm{~h}$. Cell cycle was assessed by intercalation of 4,6-diamidino-2-phenylindole dihydrochloride (DAPI) into DNA and quantification by flow cytometry. Values are means with their standard deviations depicted by vertical bars $(n 3)$. Student's $t$ test was used to calculate the difference from the respective medium control ( $P<0.05)$ and from blank $(† P<0.05)$. 

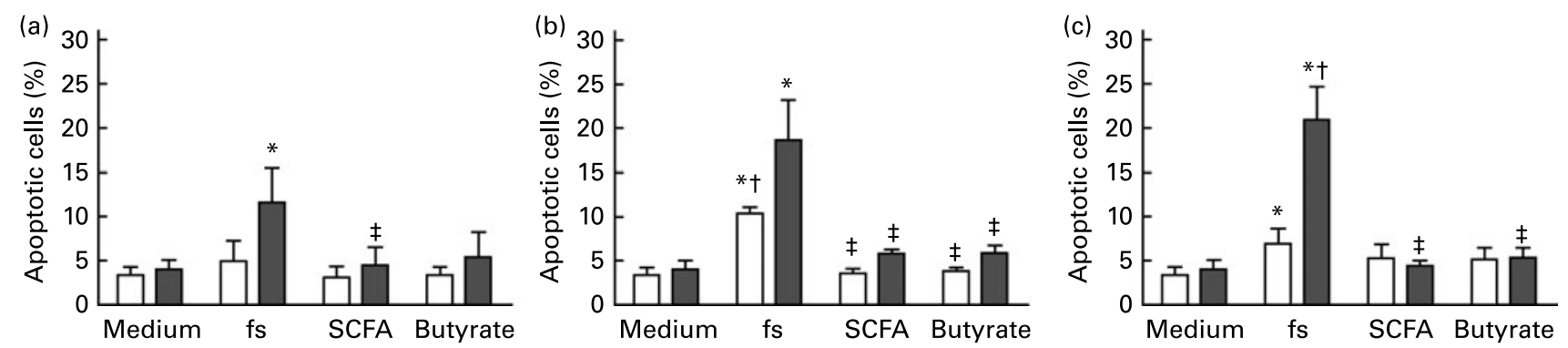

Fig. 2. Effects of fermentation supernatants (fs, $10 \%$ ), the corresponding SCFA mixtures (acetate, propionate and butyrate) and butyrate alone on early apoptosis in HT29 cells after treatment with blank (a), European aleurone (b) and American aleurone (c) for $24 \mathrm{~h}(\square)$ and $48 \mathrm{~h}$ ( $\square$ ). Apoptosis was assessed by binding of annexin $\mathrm{V}$ and exclusion of 7-amino-actinomycin D quantified by flow cytometry. Values are means with their standard deviations depicted by vertical bars $(n 3)$. Student's $t$ test was used to calculate the difference from the respective medium control $\left({ }^{*} P<0.05\right)$, from blank $(\dagger P<0.05)$ and from each $\mathrm{fs}(\ddagger P<0.05)$.

and butyrate concentrations caused a cell cycle arrest in G0/G1 phase in a similar manner like fs.

\section{Induction of apoptosis by fermentation supernatants of both aleurone varieties}

Fs of both aleurone varieties were used to analyse the effect on apoptosis as another important marker of secondary chemoprevention. The basal levels of early apoptotic cells detected in HT29 cells were 3.36 (SD 0.89) \% after $24 \mathrm{~h}$ and 4.02 (SD 1.03 ) \% after $48 \mathrm{~h}$, respectively. The fs (10\%) of different aleurone varieties (EU and US) induced a significant increase in apoptosis in HT29 cells (Fig. 2). The fs blank was able to induce apoptosis after $48 \mathrm{~h}$, but levels of apoptotic cells were significantly lower after treatment with the fs blank than with both fs aleurone. Synthetic mixtures of SCFA (acetate, propionate and butyrate) or butyrate alone had no influence on apoptosis and were significantly different from the fs. A higher butyrate concentration of $10 \mathrm{~mm}$ (positive control) significantly shifted the rate of early apoptotic cells to 10.82 (SD 2.46) \% after $24 \mathrm{~h}$ and $19.07 \%$ (SD 5.78) \% after $48 \mathrm{~h}$, respectively.

To confirm the results obtained using annexin V/7-aminoactinomycin $\mathrm{D}$ and to get more detailed information about the underlying molecular mechanisms, the influence of fs on caspase activity was measured. Fermented aleurone of both varieties (10\%) significantly induced caspase-3 activity compared with the medium control, which confirms the results obtained by flow cytometry (Fig. 3). In contrast, the fs blank did not induce the activity of caspase- 3 . Initiator caspases- 8 and -9 were not modulated by all fs (data not shown). Therefore, no information was obtained on which pathway underlies fs-dependent induction of apoptosis.

\section{Discussion}

It is a matter of debate whether dietary fibre actually does play an important role in human cancer prevention. While recent large trials document a reduction in the risk of getting CRC, other well-conducted epidemiological studies do not support the conclusion that fibre intake and colon cancer are inversely associated $^{(4)}$. Reasons for this controversy are multifaceted and possibly result from limited expressiveness of epidemiological studies ${ }^{(23)}$. Furthermore, lack of protective effects of dietary fibre may depend on less intake $(<30 \mathrm{~g}$ dietary fibre), the quality of fibre (different fermentability by colonic microflora lead to different SCFA patterns) as well as the presence or absence of phytoprotectants in the foodstuffs $^{(3,4,6,7)}$. However, the protective characteristics, which have been proven for wheat grain components in numerous studies $^{(13)}$, could be assigned neither to a single compound nor to a certain group of substances so far. There are some indications that dietary fibres of wheat bran inhibit colon tumours in animal experiments more consistently than other dietary fibres. Fermentation of dietary fibre by intestinal bacterial flora may lead to enhanced levels of potential chemoprotective metabolites such as SCFA indicated by a lower $\mathrm{pH}$ in the colon ${ }^{(4)}$. Here, fast metabolism of arabinoxylans of wheat compounds, particularly of the aleurone layer by luminal microflora, resulted in high concentrations of SCFA
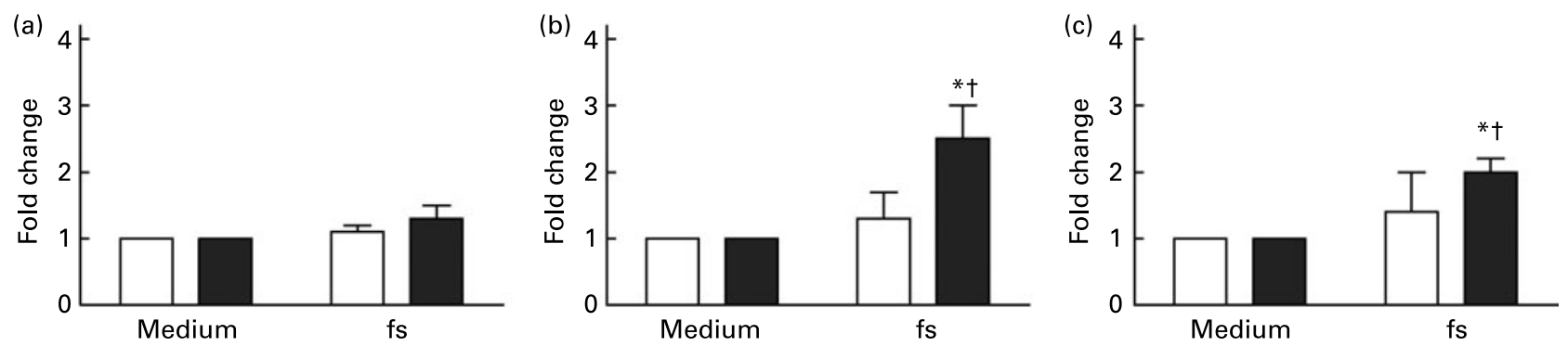

Fig. 3. Effects of fermentation supernatants (fs, $10 \%$ ) on caspase-3 activation in HT29 cells after treatment with blank (a), European aleurone (b) and American aleurone (c) for $24 \mathrm{~h}(\square)$ and $48 \mathrm{~h}(\square)$. Caspase-3 activity as an indicator for apoptotic effects was assessed in whole-cell lysates of HT29 cells in the absence and presence of caspase-3 inhibitor Ac-DEVD-CHO. Fold changes of results out of three separate experiments were calculated on the basis of the respective medium control that was set to 1.0. Values are means with their standard deviations depicted by vertical bars ( $n$ 3). Student's $t$ test was used to calculate the difference from the respective medium control $\left({ }^{*} P<0.05\right)$ and from blank $(\dagger P<0.05)$. 
and thus in a lowered $\mathrm{pH}$. Survey data from various populations showed that faecal SCFA are in the range from acetate $>$ propionate $\geq$ butyrate in a ratio of $60: 20: 20^{(3,24)}$. Depending on the diet, total SCFA concentrations in the proximal colon are $70-140 \mathrm{~mm}$ falling to $20-70 \mathrm{~mm}$ in the distal colon $^{(24)}$. Thus, the ratio of fs blank resulting from fermentation I and II of 59:18:23 and 54:23:23, respectively, fits very well to physiological conditions. In addition, the ratio of SCFA shifted from acetate to butyrate during bacterial degradation of fermentable material, primarily of arabinoxylans, contained in the investigated wheat samples. Moreover, a lowered luminal $\mathrm{pH}$ caused by increased SCFA concentrations may affect intestinal microflora by conveying growth of acidophilic bacteria species such as lactobacilli and bifidobacteria ${ }^{(25)}$.

In general, Western style diets, characterised by high concentrations of fat and animal protein, as well as low amounts of fibre, fruits and vegetables, are connected with a high release of bile acids, which seems to be a risk factor for the development of colon cancer ${ }^{(2)}$. Especially, secondary bile acids, produced by bacterial conversion of primary bile acids, showed tumour-promoting properties by acting directly on the mucosa or by promoting the effects of carcinogenic substances present in the lumen ${ }^{(26)}$. The present results demonstrated that fermentation of wheat sources extensively lowered the concentration of the secondary bile acid DCA. Next to a reduced solubility and conversion of bile acids, a lower $\mathrm{pH}$ also can reduce the activity of the enzyme 7 - $\alpha$-dehydroxylase, which is responsible for the conversion of primary to secondary bile acids ${ }^{(27)}$. An increase in number and activity of acidophilic bacteria strains could lead to an enhanced binding of bile acids by these bacteria ${ }^{(26)}$. Furthermore, direct binding of bile acids by dietary fibre could also lead to reduced concentrations in the gut lumen ${ }^{(28)}$. Since bile acids are presumed to promote colon cancer growth and progression $^{(29)}$ and are known to interfere with antiproliferative properties of butyrate ${ }^{(26,30)}$, this observed decline in bile acids in the presence of dietary fibre can be considered to be favourable in terms of colon cancer prevention.

Ammonia, which is a product from proteolytic bacterial fermentation in the distal colon ${ }^{(3)}$, could also promote colon cancer, since ammonia exhibits a number of effects on the colonic mucosa, including increased mucosal cell turnover and the incidence of colon carcinomas induced by $N$-methyl- $N^{\prime}$-nitro$N$-nitrosoguanidine in rats ${ }^{(31)}$. Dietary fibre sources are thought to reduce ammonia concentrations in the intestinal lumen. This is attributed to their role as bacterial substrates resulting either in an increased utilisation of ammonia for bacterial cell growth or a reduced deamination of nitrogenous compounds ${ }^{(32)}$ or indirectly by lowering the $\mathrm{pH}$ and so affecting enzyme activity e.g. of amino acid decarboxylase ${ }^{(33)}$. In the present study, the ammonia concentration in all fs showed a direct correlation to the protein content of the test substances. Therefore, fermented aleurone exhibited the highest amounts of ammonia. Cummings et al. ${ }^{(32)}$ showed that fibre sources with relatively high-protein contents diminish the ammonia-lowering effect of fibre. So, non-cereal dietary fibre sources that contain less protein may be more effective at lowering faecal ammonia levels than fibres from wheat grains.

Secondary chemoprevention is defined as the use of natural, synthetic or biological agents to reverse or suppress the promotion and progression of neoplastic cells to cancer $^{(34)}$. Investigations on effects of the fs on the growth of transformed cells as a useful indicator of secondary chemoprotection showed that the growth of HT29 cells was efficiently retarded by all fs in a time- and dose-dependent manner, with increased effectiveness of the fermented wheat samples compared to the faeces control. No important differences were seen between different wheat fractions and aleurone varieties. Hence, fermentable dietary fibre, concentrated in the aleurone layer, seems to be responsible for the growth-inhibitory effects of whole-wheat grains. In this study, SCFA were the major biologically active and growthinhibitory components in the fs of wheat samples, especially aleurone. However, the fermentation samples were more effective in inhibiting the cell growth than the synthetic SCFA mixtures. These findings are in line with previous experiments in which several fs of various fibre sources were analysed for their effects on cell growth and survival ${ }^{(6)}$. Even though it has been hypothesised that butyrate is the primarily SCFA, which inhibits colon tumour cell proliferation $^{(35,36)}$, results of Beyer-Sehlmeyer et al. ${ }^{(6)}$ and Gamet et al. ${ }^{(37)}$ indicate that propionate also exhibits appreciable antiproliferative properties. The present study showed that the cell growth-inhibiting effects of SCFA in the fermented wheat sources are caused almost solely by butyrate. Propionate concentrations comparable with concentrations found in fs aleurone $(2 \mathrm{mM})$ exhibited an antiproliferative effect only after $8 \mathrm{~d}$ of treatment ${ }^{(38)}$. Coradini et al. ${ }^{(36)}$ have demonstrated that $4 \mathrm{~mm}$ butyrate for $72 \mathrm{~h}$ reduces the growth of HT2 cells by $75 \%$. A comparable growth reduction (60-70\%) was found in the present work in cells treated with butyrate concentrations contained in $20 \%$ fs of wheat sources $(3 \cdot 7-5.9 \mathrm{mM})$. In comparison, the fs reduced cell growth by $95 \%$. Thus, the growth-inhibiting effect of the fs in the present study is probably not only due to the butyrate content. The additional activity of the fermentation samples reflects the growth-inhibitory properties of other metabolites, which have not yet been identified, or synergistic effects of these metabolites with SCFA. Furthermore, fs blank, containing less amounts of SCFA than the fermented wheat samples, also efficiently reduced cell growth. Glei et al. ${ }^{(17)}$ suggested that secondary bile acids possibly cause the effects of fs blank on cell number. But, the DCA concentrations found in fs blank ( $7 \mu \mathrm{M}$ in $20 \% \mathrm{fs}$ ) as well as the concentrations of ammonia ( $4 \mathrm{~mm}$ in $20 \%$ ) are too low to affect cells (data not shown). Thus, so far, unidentified metabolites probably resulting from the faecal inoculum must be partially responsible for the cell-modulating effects of fs blank. Growth inhibition by unfermented extracts of wheat sources is possibly caused by the presence of free phenolic acids, which have been shown to act antiproliferative in colon tumour cells ${ }^{(39)}$.

Additionally, the impact of the fs on cell cycle modulation was investigated to enhance our knowledge about mechanisms, which could be responsible for the effects on cell growth. Butyrate has been shown to inhibit cell proliferation by arresting cell cycle in the G0/G1 phase by a mechanism of action still not completely understood ${ }^{(40)}$. The present results indicated that fs aleurone independently of the variety inhibited HT29 cell growth after $48 \mathrm{~h}$ related to blocking cells in the G0/G1 phase of the cell cycle. This impact is attributed to butyrate's effect, since butyrate mimicking the concentration of fs 
aleurone $(2-2.4 \mathrm{~mm})$ caused a cell cycle arrest in the G0/G1 phase in a similar manner. Fs blank, in which only low concentrations of butyrate were found $(0.5 \mathrm{~mm})$, did not modulate cell cycle progression. G0/G1 arrest induced by butyrate is related to a downregulation of genes involved in cell proliferation ${ }^{(41)}$. Results of Coradini et al. ${ }^{(36)}$ indicated that butyrate $(>1 \mathrm{~mm})$ reduced cyclin D1 and maintained the synthesis of $\mathrm{p} 21^{\text {waf } 1 / \mathrm{cip} 1}$, probably in a p53-independent way. Overexpression of p21 waf1/cip1 selectively inhibits the G1/S cdk-cyclin complexes; thus, it is inversely associated with proliferation and directly affects terminal differentiation $^{(5)}$.

In addition to growth inhibition, induction of apoptosis is another relevant marker for secondary chemoprevention of CRC. Although the molecular basis for the proapoptotic effects of butyrate has not been fully worked out, there are indications that extrinsic as well as intrinsic pathways of programmed cell death are involved ${ }^{(5,42)}$. In contrast, effects of fs or SCFA mixtures have not been well investigated. Using annexin $\mathrm{V}$ staining, the externalisation of phosphatidylserine as an early event in apoptosis could be detected after treatment of HT29 cells with the fs. Fs aleurone (10\%) independently of variety (EU and US) was able to induce apoptosis in a timedependent manner and was more effective than the fs blank, although fs blank also had proapoptotic effects in HT29 cells. Beyond this, the proapoptotic effects of the fs aleurone resulted in an enhanced activity of caspase-3. Caspase- 3 is a member of a cysteine protease family that is involved in the execution of the apoptotic programme. Since fs aleurone did not induce activities of caspase- 8 or -9 , no information is given if the extrinsic or intrinsic pathway plays a role in activation of apoptosis. Therefore, experimental conditions like the time frame or less sensitivity of the method could be the reason for the lack of induction of the initiator caspases. Furthermore, SCFA (acetate, propionate and butyrate) or butyrate mimicking the concentration in the fs did not enhance the level of apoptotic cells. A study by Medina et al. ${ }^{(43)}$ has shown that butyrate ( $4 \mathrm{~mm})$ induces activation of caspase-3 in CRC cells. Kim et al. ${ }^{(42)}$ suggested that butyrate sensitises human cancer cells to TRAIL-mediated apoptosis by upregulation of expression of death receptor DR5 that is mediated by activation of Sp1-transcriptional factor. In HT29 cells, 4 mM butyrate induced a 2.4-fold increase in DR5 expression, whereas lower concentrations $(2 \mathrm{mM})$, found in our fs, did not modulate expression levels. In addition, only higher butyrate concentrations $(>5 \mathrm{~mm})$ enhanced histone acetylation resulting in reactivation or silencing of genes critical for apoptosis $^{(22)}$. Therefore, further studies are needed to identify which molecular cascades are involved in the proapoptotic activity of fs and which metabolites are responsible for its effect.

In conclusion, the present results provide evidence on the biological effects of fermentation samples from different wheat sources, in particular aleurone. Gut flora-mediated fermentation of wheat aleurone results in reduced levels of tumour-promoting DCA but higher levels of potentially chemopreventive SCFA, especially butyrate. The aleurone layer was identified as the most beneficial subfraction, since its fermentation metabolites were able to induce apoptosis and to block cell cycle - two essential markers of secondary chemoprevention. Partly, chemoprotective activities of fermented aleurone are caused by butyrate. Thus, a fibre-rich diet (e.g. with aleurone-enriched products) could be an effective strategy, firstly to enhance gut health and secondly to inhibit growth of transformed colon cells.

\section{Acknowledgements}

We would like to thank the Federal Ministry of Education and Research, Germany (BMBF 0313829A) for funding. The authors have no conflicts of interest. A. B., K. S., D. S. and M. G. designed the research and wrote the paper. A. B. and $\mathrm{K}$. S. performed the in vitro fermentation and experiments on cell growth. A. B. performed the experiments on quantification of cell cycle parameters and apoptosis. K. S., G. B-.W. and U. O. performed the analysis of SCFA and bile acids and wrote the part describing the corresponding methods. J. H. and M. L. performed the analysis of dietary fibre sources that were provided by N. W. We thank Walter von Reding, Bühler AG, Switzerland, for preparation of the aleurone fraction from wheat sources.

\section{References}

1. Parkin DM, Bray F, Ferlay J, et al. (2005) Global cancer statistics, 2002. CA Cancer J Clin 55, 74-108.

2. World Cancer Research Fund (2007) Food, Nutrition, Physical Activity, and the Prevention of Cancer: A Global Perspective. Washington, DC: American Institute for Cancer Research.

3. Hamer HM, Jonkers D, Venema K, et al. (2008) Review Article: the role of butyrate on colonic function. Aliment Pharmacol Ther 27, 104-119.

4. Young GP, Hu Y, Le Leu RK, et al. (2005) Dietary fibre and colorectal cancer: a model for environment-gene interactions. Mol Nutr Food Res 49, 571-584.

5. Williams EA, Coxhead JM \& Mathers JC (2003) Anti-cancer effects of butyrate: use of micro-array technology to investigate mechanisms. Proc Nutr Soc 62, 107-115.

6. Beyer-Sehlmeyer G, Glei M, Hartmann E, et al. (2003) Butyrate is only one of several growth inhibitors produced during gut flora-mediated fermentation of dietary fibre sources. $\mathrm{Br}$ J Nutr 90, $1057-1070$.

7. Munjal U, Glei M, Pool-Zobel BL, et al. (2009) Fermentation products of inulin-type fructans reduce proliferation and induce apoptosis in human colon tumour cells of different stages of carcinogenesis. Br J Nutr 1-9 (Epublication ahead of print version).

8. Wang X \& Gibson GR (1993) Effects of the in vitro fermentation of oligofructose and inulin by bacteria growing in the human large intestine. J Appl Bacteriol 75, 373-380.

9. Aura A-M, Härkönen H, Fabritius M, et al. (1999) Development of an in vitro enzymic digestion method for removal of starch and protein and assessment of its performance using rye and wheat breads. J Cereal Sci 29, 139-152.

10. Amrein TM, Gränicher P, Arrigoni E, et al. (2003) In vitro digestibility and colonic fermentability of aleurone isolated from wheat bran. Lebensm -Wiss U -Technol 36, 451-460.

11. Buri RC, von Reding W \& Gavin MH (2004) Description and characterization of wheat aleurone. Cereal Foods World 49, 274-281.

12. Ferguson LR \& Harris PJ (1999) Protection against cancer by wheat bran: role of dietary fibre and phytochemicals. Eur $J$ Cancer Prev 8, 17-25.

13. Lupton JR \& Turner ND (1999) Potential protective mechanisms of wheat bran fiber. Am J Med 106, 24S-27S. 
14. Reddy BS (1999) Role of dietary fiber in colon cancer: an overview. Am J Med 106, 16S-19S.

15. Baublis AJ, Lu C, Clydesdale FM, et al. (2000) Potential of wheat-based breakfast cereals as a source of dietary antioxidants. J Am Coll Nutr 19, 308S-311S.

16. Hollmann $\mathrm{J} \&$ Lindhauer MG (2005) Pilot-scale isolation of glucuronoarabinoxylans from wheat bran. Carbohydrate Polymers 59, 225-230.

17. Glei M, Hofmann T, Kuster K, et al. (2006) Both wheat (Triticum aestivum) bran arabinoxylans and gut flora-mediated fermentation products protect human colon cells from genotoxic activities of 4-hydroxynonenal and hydrogen peroxide. J Agric Food Chem 54, 2088-2095.

18. Wang JF, Zhu YH, Li DF, et al. (2004) In vitro fermentation of various fiber and starch sources by pig fecal inocula. J Anim Sci 82, 2615-2622.

19. Burkard I, von Eckardstein A \& Rentsch KM (2005) Differentiated quantification of human bile acids in serum by high-performance liquid chromatography-tandem mass spectrometry. J Chromatogr B Analyt Technol Biomed Life Sci 826, 147-159.

20. Chaney AL \& Marbach EP (1962) Modified reagents for determination of urea and ammonia. Clin Chem 8, 130-132.

21. Glei M, Matuschek M, Steiner C, et al. (2003) Initial in vitro toxicity testing of functional foods rich in catechins and anthocyanins in human cells. Toxicol In Vitro 17, 723-729.

22. Kiefer J, Beyer-Sehlmeyer G \& Pool-Zobel BL (2006) Mixtures of SCFA, composed according to physiologically available concentrations in the gut lumen, modulate histone acetylation in human HT29 colon cancer cells. Br J Nutr 96, 803-810.

23. Schatzkin A \& Kipnis V (2004) Could exposure assessment problems give us wrong answers to nutrition and cancer questions? $J$ Natl Cancer Inst 96, 1564-1565.

24. Wong JM, de Souza R, Kendall CW, et al. (2006) Colonic health: fermentation and short chain fatty acids. J Clin Gastroenterol 40, 235-243.

25. Blaut M (2002) Relationship of prebiotics and food to intestinal microflora. Eur J Nutr 41, Suppl. 1, I11-I16.

26. Zampa A, Silvi S, Fabiani R, et al. (2004) Effects of different digestible carbohydrates on bile acid metabolism and SCFA production by human gut micro-flora grown in an in vitro semi-continuous culture. Anaerobe 10, 19-26.

27. Owen RW (1986) The metbolism of bile acids. In Microbial Metabolism in The Digestive Tract, pp. 51-65 [MJ Hill, editor]. Boca Raton, FL: CRC Press.

28. Das D, Arber N \& Jankowski JA (2007) Chemoprevention of colorectal cancer. Digestion 76, 51-67.

29. Pai R, Tarnawski AS \& Tran T (2004) Deoxycholic acid activates beta-catenin signaling pathway and increases colon cell cancer growth and invasiveness. Mol Biol Cell 15, 2156-2163.
30. McMillan L, Butcher S, Wallis Y, et al. (2000) Bile acids reduce the apoptosis-inducing effects of sodium butyrate on human colon adenoma (AA/C1) cells: implications for colon carcinogenesis. Biochem Biophys Res Commun 273, 45-49.

31. Hughes R, Magee EA \& Bingham S (2000) Protein degradation in the large intestine: relevance to colorectal cancer. Curr Issues Intest Microbiol 1, 51-58.

32. Cummings JH, Hill MJ, Bone ES, et al. (1979) The effect of meat protein and dietary fiber on colonic function and metabolism. II. Bacterial metabolites in feces and urine. Am J Clin Nutr 32, 2094-2101.

33. Cummings JH \& Englyst HN (1987) Fermentation in the human large intestine and the available substrates. Am J Clin Nutr 45, $1243-1255$.

34. Bonovas S, Tsantes A, Drosos T, et al. (2008) Cancer chemoprevention: a summary of the current evidence. Anticancer Res 28, 1857-1866.

35. Ruemmele FM, Dionne S, Qureshi I, et al. (1999) Butyrate mediates Caco-2 cell apoptosis via up-regulation of pro-apoptotic BAK and inducing caspase- 3 mediated cleavage of poly-(ADP-ribose) polymerase (PARP). Cell Death Differ 6, 729-735.

36. Coradini D, Pellizzaro C, Marimpietri D, et al. (2000) Sodium butyrate modulates cell cycle-related proteins in HT29 human colonic adenocarcinoma cells. Cell Prolif 33, 139-146.

37. Gamet L, Daviaud D, Denis-Pouxviel C, et al. (1992) Effects of short-chain fatty acids on growth and differentiation of the human colon-cancer cell line HT29. Int J Cancer 52, 286-289.

38. Siavoshian S, Blottiere HM, Le FE, et al. (1997) Comparison of the effect of different short chain fatty acids on the growth and differentiation of human colonic carcinoma cell lines in vitro. Cell Biol Int 21, 281-287.

39. Ferguson LR, Zhu ST \& Harris PJ (2005) Antioxidant and antigenotoxic effects of plant cell wall hydroxycinnamic acids in cultured HT-29 cells. Mol Nutr Food Res 49, 585-593.

40. Blottiere HM, Buecher B, Galmiche JP, et al. (2003) Molecular analysis of the effect of short-chain fatty acids on intestinal cell proliferation. Proc Nutr Soc 62, 101-106.

41. Iacomino G, Tecce MF, Grimaldi C, et al. (2001) Transcriptional response of a human colon adenocarcinoma cell line to sodium butyrate. Biochem Biophys Res Commun 285, 1280-1289.

42. Kim YH, Park JW, Lee JY, et al. (2004) Sodium butyrate sensitizes TRAIL-mediated apoptosis by induction of transcription from the DR5 gene promoter through Sp1 sites in colon cancer cells. Carcinogenesis 25, 1813-1820.

43. Medina V, Edmonds B, Young GP, et al. (1997) Induction of caspase- 3 protease activity and apoptosis by butyrate and trichostatin A (inhibitors of histone deacetylase): dependence on protein synthesis and synergy with a mitochondrial/ cytochrome c-dependent pathway. Cancer Res 57, 3697-3707. 